\section{de Psicologia}

ISSN 2179-1740

\title{
REFORMA TRABALHISTA: UMA ANÁLISE PSICOSSOCIAL
}

\author{
LABOR REFORM: A PSYCHOSOCIAL ANALYSIS
}

\section{Marcelo Afonso Ribeiro ${ }^{1}$}

\section{Resumo}

O trabalhar segue sendo atividade central na vida das pessoas na contemporaneidade e o Estado cumpre importante papel na regulação e estruturação do mundo do trabalho como promotor de segurança e proteção social. O governo brasileiro aprovou uma reforma trabalhista buscando flexibilizar para aumentar produtividade, competitividade e formalização do trabalho. Críticos à reforma apontam que a flexibilização irá aumentar a precarização do trabalho. Através do método de análise documental do texto da Reforma Trabalhista, o presente artigo visou discutir possibilidades, problemas e contradições desta reforma a partir de uma análise psicossocial. As principais conclusões indicaram que a Reforma Trabalhista, ao ser pautada na individualização, flexibilização e livre negociação no trabalho, traz uma dupla consequência. De um lado, irá beneficiar empresários/as e trabalhadores/as de alta renda e qualificação, sendo a flexibilização benéfica para as relações de trabalho. E, por outro lado, irá dificultar o suporte social demandado pela maioria de trabalhadores/as ao enfraquecer os sindicatos e relativizar os suportes e proteções sociais via Estado com a possível consequência de maior vulnerabilidade de grande parte dos/as trabalhadores/as, sendo uma flexibilização do trabalho geradora de precarização.

Palavras-chave: Mercado de trabalho; justiça social; vulnerabilidade; individualização; psicossocial.

\begin{abstract}
Working continues to be a core activity in people's lives in contemporary and the State fulfills an important role in regulating and structuring working world as the promoter of security and social protection. Brazilian government has approved a labor reform which aims to make existing systems more flexible to enhance productivity, competitiveness and formalization of employment relationships. Reform critics indicate that flexibilization will increase precariousness of work. Through a documentary analysis, this paper aimed to discuss the possibilities, problems and contradictions of the reform from a psychosocial analysis. The main contribution this paper offers is the twofold consequence of a Labor Reform based on individualization, flexibilization and free negotiation of employment relationships. On the one hand, it will chiefly benefit entrepreneurs and highly skilled and high-income workers, what turns working flexibilization into a beneficial outcome. And, on the other hand, it will hamper the social supports required by most of the workers when weakening trade unions and relativizing social protections provided by State actions. One possible consequence is more vulnerability of most of workers, what turns working flexibilization into working precariousness.
\end{abstract}

Keywords: Labor market; social justice; vulnerability; individualization; psychosocial.

1 Instituto de Psicologia da Universidade de São Paulo. Brasil. E-mail: marcelopsi@usp.br. http://orcid.org/0000-0002-0396-7693 


\section{INTRODUÇÃO}

A lógica capitalista de aumento da produtividade e competitividade para o desenvolvimento econômico contínuo em função da internacionalização e globalização da economia tem demandado do Estado ações que visem garantir estes objetivos, ao mesmo tempo em que ele deve igualmente cuidar do desenvolvimento social do país.

Uma esfera socioeconômica central para a realização destes objetivos é o mundo do trabalho e o Estado deve regulá-lo a fim de gerar tanto desenvolvimento econômico, quanto social. É no interior deste quadro que a Consolidação das Leis de Trabalho (CLT) originariamente proposta pelo Decreto-Lei n. ${ }^{0} 5$ 452, de 1 de maio de 1943 (Brasil, 1943), foi atualizada, de forma significativa, pela chamada Reforma Trabalhista, na Lei $n^{0} 13.467$, de 13 de julho de 2017 (Brasil, 2017).

A CLT vem sofrendo alterações desde sua proposição inicial, mas a Reforma Trabalhista operou modificações profundas a fim de atender as demandas capitalistas atuais, o que vem gerando uma série de questionamentos e críticas da sociedade brasileira em seus mais variados setores (Campos, 2017; Carvalho, 2017; Costa, Costa, \& Cintra, 2018; Krein, 2018; Oliveira \& Figueiredo, 2017; Silva, 2018). A principal justificativa do governo para a reforma foi flexibilizar as leis relativas ao direito do trabalho em nome do aumento da produtividade e competitividade do país com consequente ampliação da formalização do trabalho em decorrência destes aumentos (Carvalho, 2017; Silva, 2018). Críticos a este tipo de reforma apontam, justamente, que a flexibilização irá aumentar a precarização do trabalho e não sua formalização, como preconizado (Adascalitei \& Morano, 2015; Carvalho, 2017; Krein, 2018).

Por conta da Reforma Trabalhista ser um fato recente, não se pode ainda avaliar seus impactos nem para 0 mundo do trabalho, nem para os trabalhadores/as, entretanto faz-se necessário fazer projeções do que poderá acontecer para balizar a sociedade, principalmente visando propor análises e construir hipóteses sobre 0 que predominará: a formalização de trabalhos precários ou a precarização de trabalhos formais?

As Ciências Sociais e Políticas, a Economia, a Medicina e, principalmente, o Direito têm se dedicado a fazer análises e projeções sobre a Reforma Trabalhista, e a Psicologia não poderia se eximir desta tarefa também. Com base nas argumentações preliminares apresentadas e na perspectiva da Psicologia Social, o presente artigo visou discutir possibilidades, problemas e contradições da Reforma Trabalhista a partir de uma análise psicossocial da Lei ${ }^{0}$ 13.467, de 13 de julho de 2017 (Brasil, 2017).

Para tal, realizamos uma análise documental do texto da Reforma Trabalhista (Brasil, 2017) utilizando a PWT ( Psychology of Working Theory - Teoria da Psicologia do Trabalhar), de enfoque psicossocial, proposta por Blustein (2006, 2013) e Duffy, Blustein, Diemer e Autin (2016) como base teórica principal, complementadas pelas ideias e concepções sociológicas de Bourdieu (2002/1971) e Castel (1997, 2005, 2009).

\subsection{Quadro teórico}

Partimos de duas premissas: (a) 0 trabalhar segue sendo atividade central na vida das pessoas na contemporaneidade (Antunes, 2015; Blustein, 2013; Lessa, 2002), e (b) o Estado cumpre importante papel na regulação e estruturação do mundo do trabalho como promotor de segurança e proteção social (Castel, 2005, 2009; Touraine, 2006). 


\subsubsection{Centralidade do trabalho}

Primeiramente, devemos esclarecer que, inspirados na reflexão de Blustein (2006), iremos utilizar a expressão trabalhar ao invés de trabalho, pois trabalhar é uma concepção dinâmica definida por uma ação em dado contexto (verbo que indica ação e processo), enquanto que trabalho é uma concepção mais abstrata e estruturada construída em dado contexto e apropriada por outros (substantivo que indica um estado mais permanente e estável). Desta maneira, trabalhar coloca a concepção abstrata de trabalho em ação por meio da atividade humana em dado contexto.

Defendemos a concepção de que o trabalhar segue sendo atividade central na vida das pessoas na contemporaneidade, pois 0 trabalhar seria responsável pela segurança ontológica, material e social no capitalismo (Lessa, 2002). Segundo Castel (2005), aqueles/as que têm propriedade (capital) obtém segurança via capital, enquanto aqueles/as que não têm propriedade (capital) obtém segurança via trabalhar, sendo o segundo grupo de pessoas composto pela maioria da população mundial.

Para Blustein (2013), "o trabalhar tem o potencial de atender a três necessidades humanas fundamentais - a necessidade de sobrevivência e poder; a necessidade de conexão social; e a necessidade de autodeterminação" ( $p$. 8), se configurando, assim, como um trabalhar decente (International Labour Organization, ILO, 1999).

Para tal, Duffy et al. (2016) preconizam quatro fatores preditores para que o trabalhar possa cumprir as necessidades humanas fundamentais descritas anteriormente e se constituir enquanto um trabalhar decente, a saber: (a) restrições econômicas, principalmente advindas da classe social de cada um ou do habitus de classe (Bourdieu, 2002/1971); (b) marginalização, desvantagens sociais geradas pela interseccionalidade de fatores de classe, gênero/sexualidade e raça/etnia; (c) volição do trabalho ou possibilidade de escolhas no trabalho; e (d) adaptabilidade de carreira, ou seja, capacidade de adaptação e mediação na relação das pessoas com contextos.

Duffy et al. (2016) colocam ainda que os moderadores das possiveis relações entre trabalhar decente e os preditores para que o trabalhar decente aconteça seriam: (a) personalidade proativa ou a capacidade de influenciar 0 contexto e obter sucesso; (b) consciência crítica (Freire, 1974) ou a compreensão do lugar das pessoas nas relações sociais de poder e criação dialógica de estratégias de transcendência deste lugar; (c) suporte social Ifamiliar, comunitário e institucional); e (d) condições econômicas.

Assim, o trabalhar depende de fatores psicossociais, sociais e institucionais (por exemplo, leis reguladoras como a CLT) para atender as necessidades humanas básicas e ser central na vida das pessoas, gerando realização e emancipação (Duffy et al., 2016).

\subsubsection{Papel do Estado como agente regulador do trabalho}

Castel (1997) preconiza que a construção da pessoa acontece a partir da consolidação dos suportes sociais que permitem a sua existência e destaca a importância do papel do Estado na regulação e estruturação do trabalho como promotor de segurança e proteção social, não de vulnerabilidade, pois sem trabalho as pessoas não são nada. Neste sentido, as escolhas ideológicas e políticas de cada governo irão impactar na regulação do trabalho e poderão gerar um maior ou menor grau de segurança e proteção social para um grupo maior ou menor de trabalhadores/as. 
Bourdieu (2002/1971) postula que a estrutura social é uma estrutura estruturada objetivamente atravessada pelas relações de poder em um jogo de forças e lutas, no qual a posição e a disposição de cada pessoa no campo, determinadas pelo habitus de classe, representam a distribuição de diferentes formas de capital (material, social, simbólico, político) que cada agente dispõe e que determina sua ação social ou prática. Entretanto, esta estrutura se transforma e/ou se conserva pelas relações de interação entre agentes sociais que têm posições e disposições específicas do seu habitus de classe no interior de um campo, entendido como um segmento do social, sendo, também, uma estrutura estruturante. Para o autor, toda estrutura social é pautada na dominação, o que varia é a correlação de forças. Habitus de classe são sistemas de disposições (estruturadas e estruturantes) de modos de agir, pensar, ser e fazer incorporados pela interiorização das estruturas sociais, que levam os agentes sociais a agir de dada forma em dada situação.

Castel (2009) aponta que as pessoas têm vivido, em sua maioria, polarizadas entre duas posições contemporâneas: grupo pelo excesso e grupo pela falta, sendo o segundo grupo a maioria no contexto brasileiro (ILO, 2017). $O$ grupo pelo excesso é definido por uma posição determinada pelo individualismo e pela sensação de não estar limitado pelo social, sendo a relação social um meio para a construção pessoal; enquanto que o grupo pela falta é compreendido como uma posição determinada por ausências de vínculos, suportes e proteções sociais, não pela vontade da pessoa, mas por uma vivência de processos de precarização contínuos que dificultam ser sentir um ser social pleno, apesar de continuar a sê-lo. 0 primeiro grupo é marcado pelo individualismo moderno, no qual as pessoas são "senhoras de seus empreendimentos, perseguidoras de seus interesses e desafiadora de todas as formas coletivas de enquadramento" (Castel, 1997, p. 596-597), embora permaneçam desprotegidas (chamadas de empreendedores/as). E o segundo grupo é marcado pelo individualismo negativo, ou seja, um individualismo por falta de referências, não por excesso de investimentos subjetivos, produto do enfraquecimento ou perda das referências sociolaborais. 0 primeiro grupo não demanda suportes sociais, enquanto que o segundo grupo precisa de suportes sociais fortes.

A base político-ideológica de uma reforma trabalhista com suas consequentes concepções subjacentes vai determinar sua capacidade de atender as três necessidades humanas fundamentais preconizadas por Blustein (2013) e gerar a segurança e a proteção social necessárias para uma vida digna marcada pela possibilidade de um trabalhar decente (Duffy et al., 2016; ILO, 1999).

\subsection{Revisão de literatura: análises preliminares publicadas}

Em função da Reforma Trabalhista ser uma lei recente, as análises já desenvolvidas são preliminares, principalmente se focando na área de Direito, entretanto, em sua maioria, indicaram problemas na proposta de várias ordens.

Em termos legais, a maioria dos textos advindo do Direito identificou problemas de inconstitucionalidade na Reforma Trabalhista ao se contrapor, em muitas partes, à Constituição Brasileira e à outras leis que igualmente regulamentam dimensões das relações de trabalho (Vide na íntegra Tribunal Superior do Trabalho, 2017).

Em termos conceituais, em primeiro lugar, chama a atenção o fato de que na Lei $n^{0} 13.467$ "o trabalho foi considerado em um aspecto estritamente econômico, em detrimento de seu caráter de direito fundamental social", sendo "a condição humana substituída pela mercantilização do/a trabalhador/a" (Oliveira \& Figueiredo, 2017, p. 118). 
Para Carvalho (2017), a Reforma se baseia na noção de que a relação trabalhista é determinada por uma relação entre coisas, não entre pessoas, "predominando a visão do trabalho como 'labor' e não como 'opus'" (Krein, 2018, p. 103), o que seria uma "premissa falsa, pois a força de trabalho não é uma mercadoria qualquer, pois é impossivel separá-la da pessoa do/a trabalhador/a" (Carvalho, 2017, p. 82).

Em segundo lugar, a Reforma Trabalhista iguala forças desiguais e assimétricas (trabalhador/a e empregador/a) e todo direito do trabalho tem base no consenso da desigualdade de forças existentes, considerando o/a trabalhador/a, em geral, como hipossuficiente (Campos, 2017; Carvalho, 2017; Oliveira \& Figueiredo, 2017).

E, em terceiro lugar, como indicou Carvalho (2017), a livre negociação dos acordos coletivos tem prevalência sobre a lei e a função do direito do trabalho é delimitar um quadro dentro do qual a livre negociação pode acontecer e não o contrário. Além disso, a Reforma Trabalhista apenas garante o processo de negociação, e não seu resultado, potencialmente colocando dificuldades para se garantir condições mínimas de dignidade humana aos/às trabalhadores/as.

Adascalitei e Morano (2015) fizeram um estudo para a Organização para a Cooperação e Desenvolvimento Econômico (OECD) que visou analisar111 países (desenvolvidos e em desenvolvimento) entre 2008 e 2014 que fizeram alterações na legislação trabalhista. Os autores apontaram que não havia relação estatisticamente significativa em nenhum dos argumentos apresentados, em geral, para justificar uma Reforma Trabalhista baseada, principalmente, na flexibilização do emprego.

Assim, o grau de proteção interna aos/às trabalhadores/as em cada país não impacta o potencial da estrutura produtiva nacional, a produtividade de um país não é explicada pelo nível de proteção em sua legislação trabalhista, não há relação entre proteção trabalhista e competitividade internacional das economias, não há relação entre proteção ao emprego e atratividade da economia, e não há a relação entre a proteção ao emprego e o nível de desigualdade econômica nos países. Em suma: o estudo concluiu que a flexibilização não aumentou 0 nível de emprego em nenhum dos países estudados e que gerou, muitas vezes, o efeito contrário, diminuindo a taxa de emprego.

Em termos sociais, Carvalho (2017), Krein (2018) e Silva (2018) dizem que a Reforma Trabalhista gera uma perda significativa do poder de barganha dos/as trabalhadores/as pelo enfraquecimento dos sindicatos e 0 aumento de poder dos/as empregadores/as. Além disso, as novas configurações do emprego parecem indicar uma legalização da precariedade acarretando, principalmente, o aumento da insegurança dos/as trabalhadores/as e a perda de direitos, bem como a diminuição da proteção social.

Costa, Costa e Cintra (2018) dizem que, em termos da saúde do/a trabalhador/a, a reforma efetuada pode incentivar um "aumento de acidentes de trabalho, doenças e incapacidades, além de maior dificuldade das garantias da Previdência Social” (p. 116).

E Campos (2017) concluí dizendo que o principal problema da Reforma foi que ela se realizou sem amplo diálogo social, como recomendam os órgãos internacionais como a Organização Internacional do Trabalho (OIT). 


\section{MÉTODO DE ANÁLISE}

Realizamos uma pesquisa documental, definida como busca de informações em materiais que não receberam nenhum tratamento científico-analítico, e podem ser caracterizados como fontes primárias, ou seja, são dados originais que possibilitam uma relação direta com os fatos a serem analisados. Segundo Sá-Silva, Almeida e Guindani (2009), um documento expressaria o acontecer histórico ou a maneira de ser em dado contexto, como testemunho deste momento. No presente artigo, a Lei $n^{0} 13.467$ (Brasil, 2017) foi o documento analisado através de duas etapas: análise documental preliminar e análise dos dados, conforme proposta de Cellard (2008).

\subsection{Análise documental preliminar}

A análise documental preliminar envolveu cinco dimensões a serem analisadas: contexto, autor (ou os/as autores/as), conceitos-chave e a lógica interna do texto, autenticidade e a confiabilidade do texto, e natureza do texto. $\mathrm{Na}$ dimensão 1 (contexto) realizamos uma análise do contexto histórico em que foi produzido o documento (Lei $\mathrm{n}^{0}$ 13.467, de 13 de julho de 2017), o universo sócio-político do autor (governo brasileiro), e para quem foi destinado/a (trabalhadores/as e empresários/as brasileiros/as). Na dimensão 2 (autor) apresentamos, de forma breve, a tendência político-ideológica do governo brasileiro, o que justificaria o teor e o direcionamento da proposta de reforma trabalhista aprovada. "Não se pode pensar em interpretar um texto, sem ter previamente uma boa identidade da pessoa que se expressa, de seus interesses e dos motivos que a levaram a escrever" (Sá-Silva, Almeida e Guindani, 2009, p. 8). Na dimensão 3 (conceitos-chave e a lógica interna do texto) identificamos os conceitos-chave presentes na Lei estudada e analisamos a lógica interna do texto em termos de construção dos argumentos que embasam a lei e do processo de argumentação desenvolvido ao longo do texto. Na dimensão 4 (autenticidade e a confiabilidade do texto) avaliamos a confiabilidade do texto como representação do fato que descreve e, o documento analisado, por se tratar de uma lei federal aprovada, por si garante sua autenticidade enquanto documento verdadeiro. E, na dimensão 5 (natureza do texto) temos como elemento de análise o fato do documento estudado ser um texto jurídico com um contexto de produção textual gerador de regulações das relações sociais, no nosso caso, das relações trabalhistas.

\subsection{Análise dos dados}

Esta etapa envolveu a síntese das informações, interpretação, determinação de tendências e proposta de inferências a partir do material sistematizado com base no quadro teórico adotado. Realizamos uma análise de conteúdo do documento e destacamos trechos que indicavam os principais pressupostos da reforma proposta, bem como as principais mudanças operadas pela nova lei, buscando analisar, de forma psicossocial, se as proposições da Reforma Trabalhista iriam promover uma maior formalização ou precarização do trabalhar.

Para tal, utilizamos o quadro teórico da Psicologia do Trabalhar (Blustein, 2006, 2013; Duffy et al., 2016) por meio dos quatro preditores propostos (restrições econômicas, marginalização, volição do trabalho e adaptabilidade de carreira) e dos moderadores das possíveis relações entre trabalhar decente e os preditores para que ele aconteça (personalidade proativa, consciência crítica, suporte social e condições econômicas), visando analisar se 0 trabalhar conseguiria cumprir as necessidades humanas fundamentais (sobrevivência e poder, conexão social e 
autodeterminação) e se constituir enquanto um trabalhar decente. De forma complementar, utilizamos os conceitos de habitus de classe, campo e capital social (Bourdieu, 2002/1971), e as lógicas do individualismo moderno e do individualismo negativo (Castel, 2005).

$\mathrm{Na}$ articulação entre os resultados das dimensões da análise documental preliminar e da análise dos dados realizada foi proposta uma discussão visando fazer inferências sobre questionamento inicial postulado.

\section{APRESENTAÇÃO DOS RESULTADOS}

Em primeiro lugar, apresentaremos os resultados da análise documental, sendo que as dimensões da autenticidade e natureza do texto já foram discutidas no método.

\subsection{DIMENSÃO 1: CONTEXTO - PANO DE FUNDO POLÍTICO E IDEOLÓGICO}

Sob a égide da lógica capitalista, produtividade, competitividade e desenvolvimento econômico parecem ser os pilares da sociedade atual (Antunes, 2015), sendo a flexibilização das regulações sociais (Touraine, 2006) e a individualização da vida cotidiana (Pelbart, 2016) as estratégias primordiais para alcançar estes fins, o que tem gerado impactos significativos nas possibilidades de desenvolvimento social.

A demanda capitalista de regulação pelas forças do mercado, gera a necessidade de regulação do Estado e da sociedade civil, o que nos traz uma questão contemporânea central: como conciliar desenvolvimento econômico com desenvolvimento social? Questão, esta, que se constrói a partir de dois interesses em confronto: de um lado, a globalização e o produtivismo (desenvolvimento econômico), e, de outro lado, a defesa dos direitos humanos básicos (desenvolvimento social), entre eles, o direito ao trabalho (Castel, 2005) e, preferencialmente, um trabalhar decente, como preconiza a OIT (ILO, 1999). Sem desenvolvimento econômico não há desenvolvimento social e sem desenvolvimento social, o desenvolvimento econômico não se sustenta (Antunes, 2015; Castel, 2005, 2009). Como equacionar esta questão?

É diante deste cenário que entram em jogo as forças ideológicas e políticas norteadoras do Estado, que deve fazer escolhas que podem atender grupos majoritários ou minoritários, de acordo com os interesses e relações de poder em jogo (Bourdieu, 2002/1971). O trabalho é atividade central para o desenvolvimento, estabilidade e segurança tanto econômico, quanto social de um país, e a regulação do Estado é fator primordial para garantir isto. Assim, é na tensão entre desenvolvimento econômico e social que a Reforma Trabalhista foi proposta, acirrada por um momento de crise com a economia estagnada, alta taxa de desemprego e aumento da informalização do trabalho (ILO, 2017). Por que uma reforma trabalhista no Brasil neste momento histórico?

Silva (2018, p. 100-101) sistematizou os principais argumentos em favor da reforma trabalhista em dois campos discursivos: campo dos argumentos institucionais e campo dos argumentos econômicos. No campo dos argumentos institucionais estão o mito da outorga (CLT teria sido um ato unilateral ditatorial de Getúlio Vargas para ter apoio das classes trabalhadoras urbanas), a matriz fascista da CLT (CLT seria inspirada Carta del Lavoro, do ditador italiano Mussolini), justiça trabalhista excessivamente tutelar e pró-trabalhador/a, e inalterabilidade (necessidade de atualização de uma lei muita antiga e anacrônica). E no campo dos argumentos econômicos estariam que a CLT original seria uma "trava para o crescimento", "fator de produção de desigualdade e de comprometimento da 
competitividade nacional" e "da elevação da produtividade", e "inibidora do influxo de investimentos estrangeiros". É importante mencionar que o impeachment da presidente Dilma Rousseff criou um contexto político favorável para a aprovação da reforma trabalhista, pois havia um discurso de crise econômica atribuída a decisões e medidas da ex-presidente que abriu espaço para apoio de parte da população, dificuldade de resistência de outra parte e nenhuma mobilização da maioria.

Em síntese, a Reforma Trabalhista foi justificada pela busca de uma maior produtividade do trabalho, maior formalização (nível de emprego) e maior segurança jurídica, como apontaram Campos (2017) e Carvalho (2017) e a análise de Silva (2018).

\subsection{Dimensão 2: Autor - Governo brasileiro}

De forma breve, podemos afirmar que o governo brasileiro tem adotado a lógica neoliberal como o modelo escolhido de tendência político-ideológica para pautar suas decisões e ações, principalmente marcada pelas privatizações, pelo livre mercado com consequente diminuição de intervenções estatais, flexibilização da legislação, pela individualização do cotidiano, e pelo foco central no desenvolvimento econômico, conforme apontam Pochmann (2017), Oliveira (2018) e Lima e Curado (2017).

A tendência político-ideológica neoliberal do governo brasileiro justificaria o teor e o direcionamento da proposta de reforma trabalhista aprovada e tem se destacado como o modelo escolhido pela maioria dos países que operaram reformas das leis de regulação do trabalho, como foi o caso brasileiro (Adascalitei \& Morano, 2015).

\subsection{Dimensão 3: Os conceitos-chave e a lógica interna do texto}

Apresentamos, aqui, os dois principais elementos de produção do documento analisado: conceitos-chave e principais mudanças propostas.

A chamada Reforma Trabalhista proposta pela Lei n 13.467 (Brasil, 2017) tem seus conceitos-chave baseados no ideário neoliberal, principalmente na flexibilização das regulações pelo Estado, na predominância da livre negociação entre as partes sobre a lei e na modificação da forma de representação dos/as trabalhadores/as na empresa. 0 Artigo 611-A, reproduzido a seguir, é emblemático das duas primeiras concepções-chave identificadas.

Art. 611-A. A convenção coletiva e o acordo coletivo de trabalho têm prevalência sobre a lei quando, entre outros, dispuserem sobre:

I - Pacto quanto à jornada de trabalho, observados os limites constitucionais;

II - Banco de horas anual;

III - Intervalo intrajornada, respeitado o limite mínimo de trinta minutos para jornadas superiores a seis horas;

IV - Adesão ao Programa Seguro-Emprego (PSE);

V - Plano de cargos, salários e funções compatíveis com a condição pessoal do empregado, bem como identificação dos cargos que se enquadram como funções de confiança;

$\mathrm{VI}$ - Regulamento empresarial;

VII - Representante dos trabalhadores no local de trabalho; 
VIII - Teletrabalho, regime de sobreaviso, e trabalho intermitente;

IX - Remuneração por produtividade, incluídas as gorjetas percebidas pelo empregado, e remuneração por desempenho individual;

$X$ - Modalidade de registro de jornada;

$X I$ - Troca do dia de feriado;

XII - Enquadramento do grau de insalubridade;

XIII - Prorrogação de jornada em ambientes insalubres, sem licença prévia das autoridades competentes do Ministério do Trabalho;

XIV - Prêmios de incentivo em bens ou serviços, eventualmente concedidos em programas de incentivo;

XV - Participação nos lucros ou resultados da empresa (Brasil, 2017).

Em primeiro lugar, flexibiliza os dispositivos sobre a jornada de trabalho (itens I, II, III, VIII, X, XI e XIII) e sobre a remuneração (itens V, IX, XIV e XV). Além disso, autoriza a jornada 12-36 para qualquer trabalhador/a (Artigo 59-A), impede o estabelecimento de vínculo empregatício com trabalhadores/as autônomos/as, mesmo em caso de relação exclusiva e contínua (Artigo 442-B) e cria uma nova forma de contrato de trabalho denominada de trabalho intermitente (Artigo 443, §3).

Art. 59-A. Em exceção ao disposto no art. 59 desta Consolidação, é facultado às partes, mediante acordo individual escrito, convenção coletiva ou acordo coletivo de trabalho, estabelecer horário de trabalho de doze horas seguidas por trinta e seis horas ininterruptas de descanso, observados ou indenizados os intervalos para repouso e alimentação.

Art. 442-B. A contratação do autônomo, cumpridas por este todas as formalidades legais, com ou sem exclusividade, de forma contínua ou não, afasta a qualidade de empregado prevista no art. 30 desta Consolidação (Brasil, 2017).

Art. $443 \S 3^{\circ}$ Considera-se como intermitente 0 contrato de trabalho no qual a prestação de serviços, com subordinação, não é contínua, ocorrendo com alternância de períodos de prestação de serviços e de inatividade, determinados em horas, dias ou meses, independentemente do tipo de atividade do empregado e do empregador, exceto para os aeronautas, regidos por legislação própria (Brasil, 2017).

Em segundo lugar, o Artigo 611-A faz prevalecer a negociação entre as partes envolvidas na relação trabalhista sob a regulação do Estado ao dizer que a "convenção coletiva e o acordo coletivo de trabalho têm prevalência sobre a lei", limitando seu poder de interferência nesta relação. Esta concepção se estende ao longo da lei e permite, por exemplo, definir, através de acordos coletivos, o que seriam insalubridade e jornadas de trabalho excessivas, conforme podemos perceber no item XII do Artigo 611-A e no parágrafo único do Artigo 611-B reproduzido a seguir.

Parágrafo único. Regras sobre duração do trabalho e intervalos não são consideradas como normas de saúde, higiene e segurança do trabalho para os fins do disposto neste artigo (Brasil, 2017)

Podemos verificar a flexibilização e preponderância da negociação coletiva sobre a lei ainda com a ampliação de que os salários sejam cada vez mais constituídos por formas alternativas e variáveis de remuneração (Artigo 611-A, item IX) que se somam ao salário e podem ser retiradas a qualquer momento com perda salarial do/a trabalhador/a (Artigo 468, §2), e com a possibilidade de remunerações diferentes para igual função dentro da mesma empresa (Artigo 461). 
Art. 461. Sendo idêntica a função, a todo trabalho de igual valor, prestado ao mesmo empregador, no mesmo estabelecimento empresarial, corresponderá igual salário, sem distinção de sexo, etnia, nacionalidade ou idade.

$\S 10$ Trabalho de igual valor, para os fins deste Capitulo, será o que for feito com igual produtividade e com a mesma perfeição técnica, entre pessoas cuja diferença de tempo de serviço para o mesmo empregador não seja superior a quatro anos e a diferença de tempo na função não seja superior a dois anos.

$\S 20$ Os dispositivos deste artigo não prevalecerão quando 0 empregador tiver pessoal organizado em quadro de carreira ou adotar, por meio de norma interna da empresa ou de negociação coletiva, plano de cargos e salários, dispensada qualquer forma de homologação ou registro em órgão público (Brasil, 2017).

Art. 468. $\S 20 \mathrm{~A}$ alteração de que trata 0 ${1^{\circ}}^{\circ}$ deste artigo, com ou sem justo motivo, não assegura ao empregado o direito à manutenção do pagamento da gratificação correspondente, que não será incorporada, independentemente do tempo de exercício da respectiva função (Brasil, 2017).

Somada a estas mudanças, a Reforma propõe uma nova regulação para trabalhadores/as considerados/as hipersuficientes em função da escolaridade e do nível salarial, aos/às quais a negociação individual é prevalente sobre a lei, assim como a arbitragem privada é permitida para a resolução de conflitos (Artigo 444).

Art. 444. Parágrafo único. A livre estipulação a que se refere o caput deste artigo aplica-se às hipóteses previstas no art. 611-A desta Consolidação, com a mesma eficácia legal e preponderância sobre os instrumentos coletivos, no caso de empregado portador de diploma de nível superior e que perceba salário mensal igual ou superior a duas vezes o limite máximo dos benefícios do Regime Geral de Previdência Social (Brasil, 2017).

Uma terceira concepção importante é a forma de estruturar a representação dos/as trabalhadores/as na empresa que é modificada em dois sentidos. Primeiramente para dar mais autonomia à representação no interior de cada empresa, com a extinção da contribuição sindical obrigatória (Artigo 579) e a criação de comissão de representantes dos empregados por empresa (Artigo 510-A), como vemos nos artigos a seguir.

Art. 510-A. Nas empresas com mais de duzentos empregados, é assegurada a eleição de uma comissão para representá-los, com a finalidade de promover-lhes o entendimento direto com os empregadores (Brasil, 2017).

Art. 579. 0 desconto da contribuição sindical está condicionado à autorização prévia e expressa dos que participarem de uma determinada categoria econômica ou profissional, ou de uma profissão liberal, em favor do sindicato representativo da mesma categoria ou profissão ou, inexistindo este, na conformidade do disposto no art. 591 desta Consolidação (Brasil, 2017).

E, em segundo lugar, para dar mais autonomia a cada trabalhador/a em particular, por exemplo, com a revogação dos $\S 1^{\circ}, 3^{\circ}$ e $7^{\circ}$ do Artigo 477 da versão anterior da CLT (Brasil, 1943) que obrigavam que a homologação da rescisão do contrato fosse feita no sindicato, na presença de defensor público ou contratado e com acesso à assistência gratuita ao/à trabalhador/a durante a homologação.

Em síntese, a valorização da negociação coletiva, a valorização da representação dos/as trabalhadores/as na empresa em detrimento da representação sindical, e a flexibilização da jornada e da remuneração são as principais mudanças identificadas. 


\section{DISCUSSÃO: UMA LEITURA PSICOSSOCIAL DA REFORMA TRABALHISTA}

Podemos dizer que a Reforma Trabalhista, ao se pautar na supremacia da livre negociação sobre a lei (Carvalho, 2017; Oliveira \& Figueiredo, 2017), na flexibilização das jornadas e das remunerações (Krein, 2018), e numa tendência de individualização das relações trabalhistas, principalmente pelo enfraquecimento dos sindicatos (Carvalho, 2017; Krein, 2018; Silva, 2018) e equiparação de forças desiguais e assimétricas - trabalhador/a e empregador/a (Campos, 2017; Carvalho, 2017; Oliveira \& Figueiredo, 2017), tenderá a favorecer as partes mais fortes nas relações trabalhistas, a saber: empregadores/as e empregados/as hipersuficientes por motivos distintos.

Os empregadores/as ganham mais poder pelas mudanças propostas na Reforma por conta do alto poder que terão para negociar a estrutura de cargos, salários e funções e pela possibilidade de negociações das relações trabalhistas centradas nos acordos coletivos locais com limitada regulação externa.

Com base em Bourdieu (2002/1971), podemos dizer que o novo campo de forças relações trabalhistas apresenta uma tendência de reversão da proteção social para o/a trabalhador/a da antiga CLT para um maior poder e controle dos/as empregadores/s na nova CLT, construída mais próxima ao habitus de classe dos/as empregadores/as.

Neste sentido, os/as trabalhadores com maior capital social, cultural e material, e com um habitus de classe semelhante aos/às empregadores/as são favorecidos/as pela individualização e pela flexibilização, buscam autonomia e tem condição de consegui-la, por isso são chamados de hipersuficientes pela lei (Brasil, 2017).

Em síntese, a correlação de forças entre trabalho e capital parece estar gerando mais poder ao capital a partir da Reforma Trabalhista.

Castel (2009) nos sugere a análise do mercado de trabalho a partir de dois grandes grupos. De um lado, temos o grupo pelo excesso, que seriam os hipersuficientes, como já descrito, principais beneficiários da Reforma por uma posição social de individualismo moderno, na qual a relação social é um instrumento para a construção pessoal. E, do outro lado, temos o grupo pela falta, que seriam os chamados hipossuficientes, por terem menor capital social, cultural e material e um habitus de classe diferente dos/as empregadores/as, serem desfavorecidos/as pela livre negociação, individualização e flexibilização, e necessitarem suporte social. Grupo marcado por uma posição social de individualismo negativo determinado pela falta de laços, suportes e proteções sociais, como parece que será o futuro de grande parte dos/as trabalhadores/as em função das mudanças impostas pela Reforma (é mister marcarmos que há posições intermediárias entre estes grupos num continuum do excesso a falta e vice-versa).

A Reforma Trabalhista tenderá a dificultar o suporte social demandado pelo grupo maior de trabalhadores/as ( grupo pela falta) ao enfraquecer os sindicatos, incentivar a livre negociação e diminuir a proteção social via Estado com uma possível consequência de aumento da vulnerabilidade de grande parte dos/as trabalhadores/as, o que é justamente o oposto do que os principais argumentos para uma reforma preconizavam (Silva, 2018). Além disso, em termos psicossociais, a Reforma Trabalhista tem grande potencial de gerar descontinuidades, instabilidades e inseguranças em função da proposta de contratos intermitentes, modificação da lógica dos temporários e autônomos e terceirização irrestrita, se constituindo em outros fatores promotores de vulnerabilidade. Somado a esta potencial consequência, esta proposta ignorou o fato de que, apesar do discurso social predominante da flexibilização do mundo do trabalho como um todo, estudos recentes colocam a busca pela estabilidade, continuidade e segurança como os modelos de carreira mais presentes no mundo do trabalho contemporâneo (Biemann, Zacher \& Feldman, 
2012; Kovalenko \& Mortelmans, 2014; Ribeiro, 2015). O que nos leva ao questionamento: incongruência, visão de futuro ou posicionamento ideológico?

Partindo do princípio de que não houve diálogo social na construção da Reforma (Campos, 2017), parece que ela foi elaborada e proposta pela imposição de dados grupos sociais detentores de maior capital financeiro, político e social, que ganham força no campo de poder das relações trabalhistas (Bourdieu, 2002/1971), valorizando a dimensão econômica sobre a social, inclusive pela mercantilização do/a trabalhador/a (Campos, 2017; Carvalho, 2017; Krein, 2018) e pelo livre mercado com consequente diminuição de intervenções estatais ao flexibilizar o poder da lei reguladora das relações trabalhistas (Lima \& Curado, 2017; Oliveira, 2018; Pochmann, 2017).

Será que a Reforma Trabalhista terá potencial de promoção das três necessidades humanas fundamentais propostas pelo enfoque teórico da Psicologia do Trabalhar proposta por Blustein $(2006,2013)$ - sobrevivência e poder, conexão social e autodeterminação -, se configurando como um trabalhar decente (ILO, 1999)? Analisemos a partir do modelo descrito em Duffy et al. (2016).

Os quatro fatores preditores para que o trabalhar possa cumprir as necessidades humanas fundamentais já descritas e ser um trabalhar decente são restrições econômicas, marginalização, volição do trabalho e adaptabilidade de carreira.

A leitura realizada com base em Bourdieu (2002/1971) apontou que a Reforma favoreceria pessoas de habitus de classe semelhantes aos/às empregadores/as, o que corresponde a uma parcela ínfima do grupo de trabalhadores/as, gerando restrições econômicas e marginalização, se constituindo preditores que indicam dificuldade da Reforma fazer com que o trabalhar supra as necessidades já descritas. Somado a isto, com base em Castel (2009), a partir da análise de que o grupo pela falta, marcado pelo individualismo negativo, teria desvantagens significativas pela Reforma, igualmente indicaria dificuldades de volição do trabalho e adaptabilidade de carreira mais características do individualismo moderno e que melhor descreve o grupo pelo excesso.

Assim, a Reforma Trabalhista parece trazer sérias dificuldades para a grande maioria dos/as trabalhadores realizar um trabalhar decente (Duffy et al., 2016), principalmente aqueles/as que necessitam de suporte e proteção social, via regulação do Estado, por não conseguirem tê-los através de esforços individualizados.

\section{CONCLUSÕES}

A leitura psicossocial proposta da Reforma Trabalhista permitiu algumas conclusões dependendo a partir de qual habitus de classe você responde. Para o/a empregador/a, a nova CLT parece impactar positivamente, pois ele/a ganha poder no campo de forças da relação capital-trabalho pelos processos de flexibilização e livre negociação. Enquanto que, para a maioria dos/as empregados/as, a nova CLT parece impactar negativamente, pois ele/a perde poder no campo de forças da relação capital-trabalho pela potencial precarização gerada pelos processos de flexibilização, principalmente pela individualização proposta, e pela relativização dos suportes e proteções sociais, ficando impedido de um trabalhar decente e ter suas necessidades básicas de sobrevivência e poder, conexão social e autodeterminação realizadas.

Em suma, tentando discutir a questão inicial proposta, podemos dizer que a flexibilização, a individualização e a livre negociação parecem ser adequadas e benéficas para pequena parte dos/as trabalhadores/as que detém algum tipo de capital e, por conseguinte, poder; e danosa para a grande maioria, o que nos leva a hipotetizar que haverá um 
predomínio da precarização da vida, não somente dos trabalhos formais, em função das mudanças proposta pela Reforma Trabalhista, ao contrário da justificativa principal para a reforma de formalização de trabalhos precários, como há havia antecipado o estudo de Adascalitei e Morano (2015).

Salientamos que tecemos projeções e que as hipóteses traçadas serão, ou não, comprovadas pela análise a posteriori da implementação da nova CLT (Brasil, 2017).

Encerramos 0 artigo tentando sintetizar o sentimento que a Reforma Trabalhista pode estar causando na grande maioria dos/as trabalhadores/as por meio de uma frase emblemática de Bourdieu (1993, p. 914-915): "Le sentiment d'être exclu de l'intérieur" (Sensação de ser excluído de dentro), ou seja, aquilo que deveria me proteger, poderá ser o fator de minha desproteção e vulnerabilidade, a saber: a nova CLT (Brasil, 2017).

\section{REFERÊNCIAS}

Adascalitei, D., \& Morano, C. P. (2015). Labour market reforms since the crisis: Drives and consequences. Genebra: International Labour Organization.

Antunes, R. (2015). O caracol e sua concha: ensaios sobre a nova morfologia do trabalho. São Paulo: Boitempo.

Biemann, T., Zacher, H., \& Feldman, D. C. (2012). Career patterns: A twenty-year panel study. Journal of Vocational Behavior, 81, 159-170. doi: 10.1016/j.jvb.2012.06.003

Blustein, D. L. (2006). The Psychology of Working. New York, NY: Routledge.

Blustein, D. L. (2013). The Psychology of Working: A new perspective for a new era. In D. L. Blustein (Ed.), The Oxford handbook of the psychology of working (p. 3-18). New York, NY: Oxford.

Bourdieu, P. (1993). La misère du monde. Paris: Seuil.

Bourdieu, P. (2002/1971). Esboço de uma teoria da prática. Lisboa: Celta.

Brasil (1943). Decreto-Lei n. ${ }^{\circ}$ 452, de 1 de maio de 1943. Aprova a Consolidação das Leis do Trabalho. Recuperado $\begin{array}{llll}\text { em } & 6 & \text { julho, } & 2018,\end{array}$ http://www2.camara.leg.br/legin/fed/declei/1940-1949/decreto-lei-5452-1-maio-1943-415500-publicacaooriginal-1-pe. html

Brasil (2017). Lei $n^{0}$ 13.467, de 13 de julho de 2017.Altera a Consolidação das Leis do Trabalho (CLT) a fim de adequar a legislação às novas relações de trabalho. Recuperado em 6 julho, 2018, de http://www2.camara.leg.br/legin/fed/lei/2017/lei-13467-13-julho-2017-785204-publicacaooriginal-153369-pl.html

Campos, A. G. (2017). A atual reforma trabalhista: possibilidades, problemas e contradições. Texto para discussão. 
Brasília, DF: Instituto de Pesquisa Econômica Aplicada.

Carvalho, S. S. D. (2017). Uma visão geral sobre a reforma trabalhista. Mercado de Trabalho: conjuntura e análise, 63, 81-94.

Castel, R. (1997). As metamorfoses da questão social. Petrópolis: Vozes.

Castel, R. (2005). A insegurança social: o que é ser protegido? Petrópolis: Vozes.

Castel, R. (2009). La montée des incertitudes. Paris: Seuil.

Cellard, A. (2008). A análise documental. In Poupart, J. et al. (Orgs.), A pesquisa qualitativa: enfoques epistemológicos e metodológicos. Petrópolis: Vozes.

Costa, B. S., Costa, S. D. S., \& Cintra, C. L. D. (2018). Os possíveis impactos da reforma da legislação trabalhista na saúde do trabalhador. Revista Brasileira de Medicina do Trabalho, 16(1),

109-117.

doi: $10.5327 / z 1679443520180097$

Duffy, R. D., Blustein, D. L., Diemer, M. A., \& Autin, K. L. (2016). The Psychology of Working Theory. Journal of Counseling Psychology, 63(2), 127-148. doi: 10.1037/cou0000140

Freire, P. (1974). Pedagogia do oprimido. Rio de Janeiro: Paz e Terra.

International Labour Organization (ILO, 1999). Report on decent work. Recuperado em 28 maio, 2015, de http://www.ilo.org/public/english/standards/relm/ilc/ilc87/rep-i.htm

International Labour Organization (ILO, 2017). World employment and social outlook: Trends 2017. Genebra: International Labour Organization.

Kovalenko, M., \& Mortelmans, D. (2014). Does career type matter? Outcomes in traditional and transitional career patterns. Journal of Vocational Behavior, 85, 238-249. doi: 10.1016/j.jvb.2014.07.003

Krein, J. D. (2018). O desmonte dos direitos, as novas configurações do trabalho e o esvaziamento da ação coletiva: consequências da reforma trabalhista. Tempo Social, 30(1), 77-104. doi: 10.11606/0103-2070.ts.2018.138082

Lessa, S. (2002). O mundo dos homens: trabalho e ser social. São Paulo: Boitempo.

Lima, R. C., \& Curado, M. P. F. (2017). O futuro do Estado no Brasil e seus impactos na sociedade: questões para 0 desenvolvimento até 2035. Texto para discussão. Brasília, DF: Instituto de Pesquisa Econômica Aplicada. 
Oliveira, E. C. (2018). A negação dos papéis civilizatórios do Estado e da seguridade social: 0 caso brasileiro no contexto de reformas do Governo Temer. Caderno Eletrônico de Ciências Sociais, 5(2), 10.24305/cadecs.v5i2.2017.19435

Oliveira, L. J., \& Figueiredo, M. F. (2017). A reforma trabalhista e liberdade contratual. Revista de Direito Econômico e Socioambiental, 8(3), 93-121.

Pelbart, P. P. (2016). Vida capital: ensaios de biopolítica. São Paulo: lluminuras.

Pochmann, M. (2017). Estado e capitalismo no Brasil. Educação \& Sociedade, 38(139), 309-330. doi: 10.1590/ES0101-73302017176603

Ribeiro, M. A. (2015). Contemporary patterns of career construction of a group of urban workers in São Paulo (Brazil). Journal of Vocational Behavior, 88, 19-27. doi: 10.1016/j.jvb.2015.02.008

Tribunal Superior do Trabalho (2017). Revista do Tribunal Superior do Trabalho, 83(4). Rio de Janeiro: Imprensa Nacional.

Sá-Silva, J. R., de Almeida, C. D., \& Guindani, J. F. (2009). Pesquisa documental. Revista Brasileira de História \& Ciências Sociais, 1(1), 1-15.

Silva, S. P. (2018). A estratégia argumentativa da reforma trabalhista no Brasil à luz de dados internacionais. Mercado de Trabalho: conjuntura e análise, 64, 99-110.

Touraine, A. (2006). Novo paradigma para compreender o mundo. Petrópolis: Vozes. 